\title{
O SENTIDO DO IDEALISMO DE HUSSERL $^{1}$
}

Carlos Morujão (UCPortuguesa) ${ }^{2}$

cmorujao@fch.lisboa.ucp.pt

Resumo: $\mathrm{O}$ presente ensaio propõe-se explicitar o sentido do idealismo de Husserl, entre as Ideias I (de 1913) e as Meditações Cartesianas (de 1931). A primeira formulação do idealismo, na obra de 1913, apresenta-o como o resultado da distinção entre a consciência e o mundo, baseada na diferença entre os respectivos modos de doação: a primeira dando-se absolutamente e sem perspectivas ou adumbramentos, o segundo dando-se como pólo de identidade numa multiplicidade de adumbramentos. A insuficiência desta formulação para fundar uma tese idealista evidencia-se no facto de Husserl ter, de imediato, acrescentado uma outra: a saber, a distinção entre o modo de ser absoluto da consciência (nulla res indiget ad existendum) e o modo de ser contingente e intencional do mundo. Porém, o sentido final destas duas distinções será apenas esclarecido nas Meditações Cartesianas. Nesta obra, Husserl caracteriza o seu idealismo - distinguindo-o do idealismo psicológico (Berkeley) e do idealismo de Kant - como uma auto-explicitação consequente do Ego enquanto sujeito de todo o conhecimento possível. Como corolário desta definição, «mundo que efectivamente é» apenas poderá significar «mundo constituído na consciência».

Palavras-chave: Idealismo; análise intencional; adumbramento; constituição.

\section{AS TRÊS TESES DO IDEALISMO DE HUSSERL}

Com o presente ensaio proponho-me explicitar o sentido do idealismo de Husserl, entre as Ideias I (de 1913) e as Meditações Cartesianas (de 1931). E se me permito insistir, desde já, sobre a necessidade de se ter em consideração estes

\footnotetext{
${ }^{1}$ Recebido: 28-09-2015/ Aceito: 12-02-2016/ Publicado online: 28-08-2016.

${ }^{2}$ Carlos Morujão é Professor Associado da Faculdade de Ciências Humanas da Universidade Católica Portuguesa, Lisboa, Portugal.
} 
limites temporais, é porque não me proponho abordar algumas problemáticas que com a questão do idealismo husserliano mantêm alguma proximidade, como seja a da "neutralidade metafísica» da fenomenologia enquanto psicologia descritiva, que Husserl defendeu nas Investigações Lógicas. Não penso, todavia, que em 1913 Husserl tenha abandonado esta posição. Pelo contrário - e nisto também insistirei, para melhor compreensão do que direi mais adiante -, julgo que ela, não só permaneceu válida para Husserl, como também estará na base da sua insistência no facto de o «idealismo» das Ideias não se poder confundir sobre qualquer outra forma historicamente conhecida de idealismo, seja ele de tipo gnosiológico, seja de tipo metafísico ${ }^{3}$.

Como já foi notado, Husserl, naquelas duas obras que referi no início, fornece-nos três justificações, não inteiramente coincidentes, para o seu idealismo. O problema com o que eu entendo serem as duas primeiras justificações, que se encontram em Ideias I - mas com o qual já não deparamos na terceira -, reside no facto de Husserl não as classificar como justificações de uma qualquer forma de idealismo, embora seja como tal que aparecem identificadas no índice temático desta obra. Elaborado por Ludwig Landgrebe, ele foi, todavia, como é sabido, autorizado pelo próprio Husserl, facto que, por isso, qualquer interpretação deverá ter em conta. De acordo com a primeira justificação - chamarlhe-ei, de agora em diante, a Tese 1, ou T1 -, que encon-

\footnotetext{
${ }^{3}$ Não me deterei, igualmente, no que diz Husserl acerca da natureza do seu idealismo em (HUSSERL 1954, pp. 269-276). Creio, no entanto, que, quer a caracterização que aí é feita do idealismo fenomenológico, quer a justificação apresentada do carácter transcendental da fenomenologia, retomam, quanto ao essencial, o que já fora dito por Husserl nas Meditações Cartesianas. Cf. (HUSSERL 1954, pp. 271-272).
} 
tramos no $\$ 42$ da obra de 1913, há um idealismo fenomenológico que resulta da distinção entre a consciência e o mundo, baseada numa diferença entre os respectivos modos de doação: a primeira dando-se absolutamente, ou seja, sem perspectivas nem adumbramentos (Abschattungen), o segundo dando-se como pólo de identidade de uma multiplicidade de adumbramentos. A insuficiência desta primeira justificação para fundar por si só uma tese idealista (admitindo que é isso que ela faz) pode deduzir-se do facto de Husserl ter, quase de imediato, acrescentado uma outra - a que chamarei Tese 2, ou T2 -, a saber, a distinção entre o modo de ser absoluto da consciência e o modo de ser contingente e intencional do mundo. Esta segunda distinção é formulada por Husserl, no $§ 49$ de Ideias I, com o auxílio da conhecida definição de substância, por Descartes, no Livro I dos Princípios de Filosofia: tal como a substância para Descartes, a consciência para Husserl nulla re indiget ad existendum (HUSSERL 1950b, p. 115) .

Sinto-me tentado a formular as justificações do idealismo em Ideias I - para as distinguir do idealismo transcendental das Meditações Cartesianas - do modo seguinte: «qualquer mundo concebível em geral é apenas pensável como relativo à existência efectiva de uma consciência». Esta formulação não se encontra nestes termos exactos na obra de 1913 (se bem que esteja presente em manuscritos contemporâneos da sua publicação ${ }^{4}$ ), o que, todavia, não julgo constituir uma razão para a não utilizar; trata-se de uma formulação que me parece ser perfeitamente compatí-

\footnotetext{
${ }^{4} \mathrm{~A}$ formulação de que me servi não se encontra exactamente desta forma em Ideias I, mas sim, de uma forma muito semelhante à que apresento acima, em (HUSSERL 2003, p. 78). Sobre esta tese em Ideias I, cf. (HUSSERL 1950b, pp. 115-116).
} 
vel com o quadro eidético-transcendental do idealismo husserliano em Ideias I e com o âmbito fundamentalmente epistemológico em que esta obra se situa.

As distinções que subjazem ao que chamei as Teses $1 \mathrm{e}$ 2 do idealismo husserliano estão igualmente presentes nas Meditações Cartesianas. No $§ 7$ desta obra, em consonância com T2, Husserl afirma que não se pode excluir a possibilidade de se tornar duvidoso que o mundo exista efectivamente, e que toda a evidência da experiência do mundo que não é uma evidência apodítica, podendo, por isso, expor-se à subversão cartesiana das evidências - carece de uma crítica da sua validade (HUSSERL 1950a, p. 57). Da mesma forma, no $\S 13$, Husserl dirá que a subjectividade constitui o campo temático de uma ciência cujo objecto, quanto ao seu ser, é independente de uma decisão quanto ao ser ou ao não-ser do mundo (HUSSERL 1950a, p. 70). E, neste mesmo parágrafo, um pouco depois da afirmação anterior, no que entendo poder ser interpretado como uma outra formulação possível de T1, Husserl afirma que o ego pode explicitar-se a si próprio ao infinito e de um modo sistemático.

Porém, tudo isto não constitui ainda o que, nas Meditações Cartesianas, aparece como uma justificação do idealismo fenomenológico, agora explicitamente designado «idealismo transcendental». Com efeito, no $§ 41$ das Meditações, Husserl caracteriza o seu idealismo - distinguindo-o do idealismo psicológico de Berkeley e do idealismo de Kant - como uma auto-explicitação consequente do Ego enquanto sujeito de todo o conhecimento possível. Chamar-lhe-ei a Tese 3, ou T3. Ela distingue-se das duas teses anteriores, em meu entender, pelo facto de não se referir à correlação entre um objecto possível e uma consciência ac- 
tual, mas sim a uma correlação apriorística entre possibilidades eidéticas puras (HUSSERL 1950a, p. 117). O meu ego fáctico, com efeito, afirma Husserl em 1931, é apenas uma possibilidade, a qual foi obtida, a partir dele, pelo processo das livres variações. $\S 40$ das Meditações Cartesianas, em cujo título se anuncia a «passagem para a problemática do idealismo transcendental», caracterizava esta mesma problemática como sendo a da constituição de objectividades eidéticas por uma consciência possível (HUSSERL 1950a, pp. 114-115). As primeiras formulações do idealismo na base desta nova posição encontram-se, provavelmente, no Manuscrito B IV 6, de 1918 (HUSSERL 2003, pp. 146 e segs.). Voltarei, no final deste ensaio, a este importante texto.

\section{AS DUAS PRIMEIRAS TESES}

Desenvolverei, de seguida, o conteúdo de cada uma das duas primeiras teses. Relativamente a $\mathrm{T} 1$, vejamos o que nos diz o $\$ 42$ de Ideias I. Husserl começa por afirmar que existe uma diferença fundamental entre Ser como vivência (Erlebnis) e Ser como coisa (HUSSERL, 1950b, p. 95), defendendo que uma vivência é percepcionável numa percepção imanente, ao passo que tal não acontece relativamente a uma coisa existente no espaço (HUSSERL, 1950b, p. 95). Husserl explica ainda que certas vivências excluem, por princípio, a imanência do seu objecto intencional: assim, por exemplo, a captação de uma vivência de consciência alheia não se pode confundir com a captação de uma qualquer fase do fluxo das vivências próprias. $\mathrm{O}$ mesmo vale, 
aliás, para qualquer outra forma de presentificação ${ }^{5}$ : por exemplo, o que é fantasiado por outra pessoa e que, por isso, transcende o meu fluxo de vivências próprio, não é, ao contrário das minhas próprias fantasias, um objecto imanente $^{6}$. Todavia, a transcendência que estará em causa nas análises do $\S 42$ é apenas a dos objectos espaciais, a qual não deve, por isso, ser confundida com aquelas outras formas de transcendência.

Por último, Husserl conclui, neste mesmo $\S 42$, que a diferença fundamental quanto aos respectivos modos de ser é aquela que se refere à distinção entre consciência e realidade, tipos de ser que são, respectivamente, não-espacial e espacial. É, por conseguinte, esta última diferença - que corresponde à referida diferença quanto aos modos de doação (Gegebenheitsweise), distintos num caso e no outro -, que funda o que chamei a Tese 1 de Husserl sobre o idealismo fenomenológico. No caso da consciência, como vimos, percepcionamos uma vivência sem adumbramentos, ao passo que, no segundo caso, percepcionamos uma coisa adumbrando-se. Onde não existe um ser espacial, não faz sentido

\footnotetext{
${ }^{5}$ Presentificação (Vergegenwärtigung) é um conceito husserliano que designa todos os tipos de realizações da consciência em que o correlato de um acto, embora dado originariamente, não o é «em carne e osso", como acontece no caso da percepção. Entre as formas possíveis de presentificação podemos incluir a recordação, a expectativa, a fantasia, a consciência de imagem e, também, tal como é dito mais acima, a experiência de um psiquismo alheio. Cf. (HUSSERL 1966, p. 41): «Percepção é aqui o acto que põe diante dos olhos qualquer coisa como sendo ela própria, o acto que constitui originariamente o objecto. O contrário é presentificação, re-presentação, como acto que não põe o objecto, como ele próprio, diante dos olhos, mas precisamente o presentifica, o põe diante dos olhos em imagem [...].»

${ }^{6}$ Julgo que é necessário recordarmo-nos de Brentano para entender plenamente o que nos diz Husserl nesta passagem. Brentano, no Capítulo I do Livro I da sua Psicologia de um Ponto de Vista Empírico, estabelece uma distinção entre os fenómenos da percepção interna e os da percepção externa, defendendo que não posso percepcionar os primeiros sem, por isso mesmo, reconhecer que são verdadeiros. (Não posso, por exemplo, sentir prazer ou dor sem ter prazer ou dor.) Já quanto aos segundos a dúvida é possível. O que Husserl nos diz na passagem que menciono mais acima é que qualquer fenómeno psíquico alheio é objecto de percepção externa e, por isso, como todos os objectos transcendentes, pode ser posto em dúvida. Cf. (BRENTANO 2005, p. 10)
} 
falar-se em adumbramentos, ou de visão a partir de pontos de vista diferentes. $\mathrm{O}$ mesmo vale para os casos de presentificação de um ser espacial, com sejam uma recordação ou uma fantasia (HUSSERL 1950b, p. 96). Ora, uma vez que esta diferença - embora fundamental de um ponto de vista fenomenológico - remete para a própria natureza da coisa percepcionada e não para a natureza do sujeito que percepciona, fará sentido falar-se aqui de idealismo?

Aliás, já o $§ 41$ de Ideias I parecera mostrar, a uma primeira abordagem, que a fenomenologia não é necessariamente um idealismo e que a análise intencional é compatível com um realismo gnosiológico. Husserl afirma claramente a necessidade de se distinguir a percepção e a coisa percepcionada e, também, que, se actos perceptivos diferentes se podem referir à mesma coisa como pólo de identidade, é justamente pelo facto de tal coisa não constituir uma componente real desses mesmos actos. Assim, girando em torno de uma mesa, tenho percepções diferentes da mesa, tal como, fechando os olhos e não tendo mais nenhum contacto sensível com a mesa que antes percepcionava, reconheço-a como sendo a mesma mesa no momento em que, ao abrir os olhos, restabeleço com ela o contacto visual (HUSSERL 1950b, p. 92) .

Bertrand Russell - um autor que, julgo, ninguém classificará como idealista - defende em 1918 uma posição muito semelhante. É certo que Russell, como ele próprio confessa, leu as Investigações Lógicas e as suas análises da percepção têm, por vezes, algo de parecido com as análises intencionais levadas a cabo no espírito de Husserl. Ora, em "On the nature of acquaintance», servindo-se também do exemplo de uma mesa, Russell defende que a impossibilidade em percepcionar em simultâneo todas as suas partes, 
ou em percepcionar todas as fases da sua existência no tempo, significa que uma mesa mais não é do que uma ficção lógica que criamos na base de impressões sensíveis descontínuas, às quais atribuímos uma mesma origem (RUSSELL 2001, pp. 172-173). Esta «ficção lógica» de Russell não me parece ser muito diferente daquilo a que Husserl chamará nas Ideias I um noema. Embora o termo «ficção» seja obviamente infeliz, Russell compreende que o objecto percepcionado é uma unidade de sentido resultante da sobreposição ou coincidência de diferentes visadas intencionais. Husserl, como sabemos, defenderá sempre que o noema não é um constructo da mente, nem uma espécie de sinal que remeteria para uma realidade exterior à mente e, em última instância, totalmente desconhecida para ela.

No índice de conceitos de Ideias I, a passagem do $§ 41$ que acima mencionei está registada sob a designação de «idealismo fenomenológico» (HUSSERL 1950b, p. 433), embora o próprio Landgrebe chame a atenção para o facto de esta designação não aparecer no texto das Ideias. Esta situação deve-nos fazer reflectir sobre as características do idealismo husserliano - ou, pelo menos, sobre as razões que levaram Husserl a caracterizar como idealista a sua própria posição filosófica - antes de o identificarmos com qualquer outra forma historicamente conhecida de idealismo. $\mathrm{O}$ próprio Husserl, antes de classificar como idealista a sua própria posição, como facilmente se verifica nos seus textos, apressa-se a esclarecer com que tipo de idealismo - nomeadamente, o «idealismo subjectivo» de Berkeley - ela não deve ser identificada.

Aliás, em Ideias I, para uma justa avaliação da natureza do seu idealismo, talvez mais importante do que uma conhecida passagem do $\S 55$, em que Husserl afasta a possibi- 
lidade de uma interpretação berkeleyana do seu pensamento, é uma outra passagem, situada no $\S 98$, no contexto da análise das estruturas noético-noemáticas. Está aí em questão o facto de a correlação noético-noemática poder ou não ser confundida com a relação entre percipi (ser percebido) e esse (ser), tal como fora estabelecida por Berkeley (HUSSERL 1950b, p. 246). Ora, Husserl reafirma que o noema não está contido na noese como um componente real desta última, embora o eidos do noema remeta para o eidos da consciência noética. Todavia, uma morfologia das vivências noéticas concretas, nomeadamente, dos seus componentes hyléticos, mostrará como estes últimos se adumbram nas várias percepções possíveis de uma coisa, ao passo que a própria coisa conservará a sua unidade e identidade (HUSSERL 1950b, p. 247).

Talvez para desfazer equívocos quanto à natureza do seu idealismo, Husserl tenha acrescentado, ainda no $\S 42$, que para qualquer Eu, real ou possível, a percepção se realiza através de adumbramentos da coisa percepcionada por uma necessidade essencial (Wesensnotwendigkeit), ligada à sua natureza espácio-temporal, e não por uma peculiaridade ocasional da coisa, ou pelo carácter contingente da nossa constituição humana (HUSSERL 1950b, p. 97). Correlativamente, pertence ao estilo (Stil) da experiência externa o facto de um objecto espacial ser apenas uma unidade intencional, ou seja, uma unidade de modos de aparecimento, da mesma forma que pertence igualmente ao seu estilo o facto de a existência efectiva de uma coisa ser também, apenas, uma ideia, ou seja, algo a ser confirmado por experiências posteriores concordantes com a experiência actual (HUSSERL 2003, p. 77). Como se depreende, tais «experiências posteriores» são em número eventualmente infinito, 
pelo que não se pressupõe que uma consciência finita as possa realizar todas. Tal não é, porém, necessário que aconteça, uma vez que não está aqui em causa a existência efectiva dessa coisa, mas sim, apenas, a possibilidade da sua existência. Basta que em cada consciência efectiva estejam pré-delineadas possibilidades de motivação para posteriores comprovações da existência real dessa coisa.

Mas o facto de Husserl afirmar que a existência é uma ideia não significa que o idealismo fenomenológico se identifique com as formas até então conhecidas de idealismo gnosiológico. Acontece que, quando dizemos que uma coisa existe, supomos a possibilidade de uma concordância entre os actos intencionais que a visam, e tal concordância só pode ser pensada como ideal, num sentido muito preciso deste último termo: (1) trata-se de uma concordância que resulta da compreensão que os diversos adumbramentos do noema remetem para um núcleo noemático idêntico; (2) trata-se, também, de uma concordância que antecipa uma confirmação futura, por actos intencionais novos, daquilo que foi estabelecido em resultado de actos anteriormente realizados.

Correlativamente, se à possibilidade ideal de existência de uma coisa se acrescenta o reconhecimento da sua existência efectiva, exige-se, então, a existência de uma consciência actual capaz de a experimentar. Só uma tal experiência garante que nada surgirá na consciência que possa remover o ser dessa coisa, ou que o transforme num ser meramente possível. Como vemos, é a identificação entre «ser transcendente» e «ser uma unidade intencional» por conseguinte «ser para uma consciência actual» - que funda, em Ideias I, o idealismo husserliano. Trata-se da mesma tese que Husserl exprime no Manuscrito F I 31, de 
Junho de 1913, segundo a qual afirmar-se que «A existe»é o mesmo que afirmar que «existe um processo de possível construção da legitimação da existência de A» (HUSSERL 2003, p. 73) .

Mas já não será o mesmo dizer: se pensarmos na totalidade dos mundos possíveis, terá de existir um deles - ou seja, um mundo actual - em que uma consciência actual faz a experiência de um certo A. Note-se que esta afirmação tem um âmbito mais restrito do que aquela que mencionámos no parágrafo anterior. Aí, a definição husserliana de idealismo deveria ser suficientemente lata para dar também conta do facto de certo tipo de transcendências, a saber, a das entidades lógico-matemáticas, estabelecerem com a consciência que as pensa uma relação diferente da que caracteriza os objectos físicos (HUSSERL 2003, p. 74). Para poderem existir, as entidades lógico-matemáticas exigem apenas uma consciência possível que as possa pensar. De facto, para elas não vale a condição sem a qual um objecto não pode ser dito existir, ou seja, a compatibilidade entre a multiplicidade dos seus adumbramentos para a consciência que efectivamente o experimenta .

O idealismo fenomenológico, porém, supõe uma segunda tese. (Chamei-lhe, mais atrás, T2.) A sua primeira formulação em Ideias I situa-se no $\S 47$, embora a encontremos igualmente exposta no mencionado Manuscrito F I 31: o mundo efectivo é o correlato da nossa experiência fáctica, por conseguinte, é um caso particular da multiplicidade de mundos possíveis, que, por seu lado, são os correlatos de modificações essencialmente possíveis da ideia de «consciência que experimenta» HUSSERL 1950b, p. 111). Husserl afirma também que existe um único mundo da experiência e que, havendo mundos em geral, as motiva- 
ções de experiência que os constituíram devem poder ser acessíveis (hineinreichen) ao meu $\mathrm{Eu}$ e a qualquer outro (HUSSERL 1950b, p. 112). Coisas que não se deixam comprovar em nenhuma experiência humana certamente que existem, mas esta situação comprova apenas os limites fácticos da experiência. No Manuscrito B IV 6, provavelmente de Setembro de 1908, Husserl referia já que um determinado objecto empírico pode ser independente de um certo Eu empírico, mas que à essência de qualquer objecto, ou seja, à multiplicidade das suas aparições intuitivas efectivas ou possíveis, pertence o facto de ser inseparável da consciência absoluta (HUSSERL 2003, p. 35). Reposta no seu contexto, esta afirmação exprime apenas uma exigência muito razoável: a de que a afirmação da existência efectiva de um objecto implica a possibilidade de uma apreensão intuitiva dele, a possibilidade de ser julgado ou presumido, ou seja, a relação com uma consciência que efectua estes actos.

Note-se que os \$\$ 47-49 ocupam um lugar especial na estrutura da «Meditação Fenomenológica Fundamental», ou seja, da Segunda Secção de Ideias I. Por um lado, eles antecedem o importante $\S 50$, onde Husserl vai caracterizar a atitude fenomenológica e declarar que a consciência pura constitui o campo temático da fenomenologia. $\bigcirc$ mais interessante, porém, é que eles, nas palavras do próprio Husserl, mais não são do que uma espécie de suplemento ao $\S$ 46. Aqui, antecipando o que no $\S 49$ será o que chamei T2, Husserl afirma que a tese do mundo é uma tese contingente, ao passo que a tese do Eu e das suas vivências é uma tese necessária; todas as coisas dadas em carne e osso podem não existir, ao passo que nenhuma vivência dada em carne e osso pode não existir. Será que, sem a Tese 2, a Tese 1, na 
opinião de Husserl, não fundamentaria suficientemente o idealismo? Por outro lado, a conexão entre as Teses 1 e 2 e a teoria da redução carece de uma explicação. Esta explicação será dada no início do $§ 50$ - e noto este ponto importante a que voltarei daqui a pouco -, após as Teses que designei por 1 e 2 terem sido claramente formuladas. No mesmo lance, fica esclarecido o carácter de «resíduo» que o $\S 49$ atribuíra à consciência, depois de desconectada a tese da atitude natural; a consciência como resíduo não é apenas aquilo que sobra depois de tudo o mais ter sido posto de lado, mas sim, sobretudo, aquilo que, uma vez posto em suspenso o carácter executivo da atitude natural, constitui o sentido de todos os correlatos intencionais desta.

\section{IDEALISMO E ANÁLISE INTENCIONAL}

No § 49 aparecem as afirmações centrais para comprovar o que chamei a Tese 2. Assim, diz Husserl (1950b p. 115) que, para o ser da consciência, entendida como uma corrente de vivências (Erlebnisstrom), não é necessário nenhum ser real, tal como aquele que se apresenta por meio de adumbramentos ou aparições. A consciência, no caso de não existir nenhum ser real, apareceria modificada, pois seria então uma consciência actual diante de um ser inexistente ou meramente possível, mas a sua própria existência enquanto consciência actual permaneceria intacta. Aqui, a Tese 2 entrelaça-se com a Tese 1 - uma vez que as aparições dão-se perpectivisticamente, ou por adumbramentos -, ao mesmo tempo que lhe alarga o alcance. Tudo o que se dá perspectivisticamente, mas também uma certa ordenação da experiência que se estabelece na base de um tal modo de doação, por outras palavras, todo o ser real, é contingente 
em face da consciência absoluta. Mas, a ser assim, é legítimo perguntar-se: poderá o mundo não ser? Ou seja: poderá o contínuo sempre concordante de experiências, as do meu Ego e as de outros Egos, ser interrompido, de tal forma que a introdução sistemática da discordância confirme a impossibilidade de haver um mundo como correlato?

Pensemos, primeiro, no seguinte: de que modo o realista e o idealista se posicionam perante o facto de ficcionarmos, por exemplo, a existência de um centauro? As Teses 1 e 2 parece poderem ser aceites por ambos, independentemente das diferenças que os separam. Em conjunto, o realista e o idealista podem admitir que o centauro é uma unidade de sentido que transcende o fluxo imanente da consciência, negar a sua existência enquanto objecto espácio-temporal e, ao mesmo tempo, reafirmar a sua condição de correlato (como qualquer outra forma de transcendência) de um acto intencional. Que se trate de um objecto de fantasia decorre obviamente do facto de tanto o poder representar como animal de um só olho e de cabelos escuros, como com dois olhos e cabelos louros. Mas que o centauro seja, da mesma forma que qualquer objecto espáciotemporal, o correlato de um acto e, por isso mesmo, transcendente em relação a ele, deixa-se facilmente demonstrar pelo facto de, visando-o eu, por exemplo, como animal com dois olhos, não poderei visá-lo, em simultâneo, como animal de um único olho (HUSSERL 2003, p. 75). Tanto num caso como no outro estamos diante de duas possibilidades ideais, mas que, nem por apenas o serem, deixam de se excluir mutuamente. Se imagino realizada uma certa possibilidade ideal, deverei igualmente imaginar uma concordância entre a multiplicidade das aparições que dela decorrem, pois terei de imaginar igualmente um Eu ao qual 
tais aparições são dadas ${ }^{7}$. Ou seja, o facto de a análise intencional - quer dizer, o método especificamente fenomenológico de analisar os actos de consciência - se instalar na correlação entre uma consciência que visa e uma objectividade por ela visada parece conceder a tal análise um estatuto prévio à distinção entre idealismo e realismo.

Todavia, não creio que seja apenas isto que Husserl nos diz. Note-se que afirmar a relatividade do ser à consciência, inclusive na sua formulação mais forte: «não podemos pensar o ser sem a consciência, embora possamos pensar esta sem aquele», não significa dizer que um fluxo concordante de experiências é a condição suficiente para que um mundo exista como seu correlato. Pode-se talvez dizer que com a hipótese de o mundo não existir estamos apenas diante de uma experiência de pensamento e não diante de uma possibilidade real. Voltarei, para tentar esclarecer esta questão, ao já citado Manuscrito F I 31, de 1913. Husserl (2003, p. 73) afirmara, como vimos, que a asserção «A existe» é equivalente à asserção «há um caminho possível para construir a existência de A». Por outras palavras, Husserl dizia-nos que nenhum objecto individual poderia existir sem que existisse uma consciência, pelo menos possível, com a qual pudesse estar em relação. Ou seja, a ideia da existência de uma coisa - mas não, obrigatoriamente, a sua existência real - prescreve a ideia da existência de uma consciência que possa fazer a experiência dela (HUSSERL 2003, p. 77). Com esta resposta, porém, não teríamos ainda abandonado completamente a atitude natural. Ter-nos-íamos apenas preparado

\footnotetext{
${ }^{7}$ Como é óbvio, no exemplo centauro, as duas possibilidades referidas - ter um único olho e cabelos pretos, ou ter dois olhos e cabelos louros - permaneceriam sempre possibilidades em aberto até que a figura do centauro se viesse a realizar num mundo efectivamente real. (Cf. HUSSERL 2003, p. 76.) Mas não é a discussão desta a questão o que aqui nos ocupa.
} 
para o fazer, reconhecendo que a necessidade de uma consciência, implicada na ideia de uma experiência possível, prescreve-nos uma outra ideia, a saber, a da preeminência da consciência que experimenta sobre o que é experimentado enquanto tal. Aceite esta preeminência da consciência, podemos, em seguida, colocar a hipótese da não existência do mundo. Mas tal hipótese não se destina a ser confirmada. Não consigo sequer imaginar o que se faria se alguma vez ela, por absurdo, obtivesse confirmação. Mas julgo conseguir perceber o que quis Husserl fazer com ela: mostrar que a tese da atitude natural não possui validade por si mesma e que, por isso, é necessária a redução transcendental. É nesta base - e apenas nela - que podemos, se interpreto bem o que Husserl nos diz, proceder a uma análise das modalidades da experiência. Assim, só admitindo a validade da tese idealista é que a referida análise se pode iniciar, apoiada na única atitude capaz de levar a cabo as consequências da tese: a redução transcendental.

Mas há talvez mais uma razão para duvidar que a resposta à nossa questão sobre a possibilidade do não ser do mundo possa ser positiva e que, por conseguinte, a concordância entre as fases de um fluxo de consciência (ou a concordância entre dois fluxos) venha a ser definitivamente interrompida. Trata-se do facto de Husserl afirmar que tudo aquilo que parece que perdemos ao realizar a redução o obtemos de novo, mas agora sob a forma de realidade constituída (SOKOLOWSKI 1964, p. 131). A Tese 2, formulada no $\S 47$, não pode por isso significar que uma "consciência que experimenta» experimenta, antes de mais, os seus próprios estados, ou as fases do seu fluxo imanente. O que, aliás, a ser verdade, tornaria inútil a própria redução transcendental. 
Regresso ao $\S 49$, no ponto onde o deixei há momentos, ao discutir a possibilidade da não existência do mundo. Logo a seguir à passagem que mencionei (HUSSERL 1950b, p. 116-117), temos uma retomada da Tese 1. Um abismo de ser separa a consciência a e a realidade, afirma Husserl, pois, no segundo caso, temos um horizonte sempre presuntivo e em adumbramento, contingente e relativo à consciência, ao passo que no primeiro temos um ser absoluto, nunca se dando por adumbramentos ou presumptivamente $\mathrm{e}$, por conseguinte, não deixando aberta a possibilidade do seu não ser. A consciência não exerce nenhuma espécie de causalidade sobre o mundo, nem pode experimentar os efeitos de uma acção causal proveniente das coisas.

\section{O IDEALISMO DAS MEDITAÇÕES CARTESIANAS}

As duas primeiras definições de idealismo, em Ideias I, respeitam rigorosamente o conhecido "princípio de todos os princípios» da fenomenologia (HUSSERL 1950b, p. 52). De facto, uma consciência actual deverá respeitar aquilo que se dá tal como se dá - ou seja, o noema perceptivo de cada experiência -, de tal modo que o processo de constituição não poderá ter por base o que não figurar numa qualquer percepção particular. As Meditações Cartesianas, porém, falar-nos-ão da constituição de objectividades para as quais a própria distinção entre possibilidade e realidade não é pertinente; trata-se, por conseguinte, de universalidades eidéticas, cuja constituição vale para qualquer consciência possível. Uma universalidade eidética consiste numa possibilidade meramente lógica e, por isso, não exige uma consciência actual que a pense. Basta, para poder existir (no 
sentido de transcender a corrente de consciência que a engendrou), que uma consciência possível a possa pensar. $\mathrm{O}$ idealismo transcendental é, para Husserl, a explicitação desta actividade constitutiva de objectividades ideais por uma consciência possível. Mas o que Husserl defendera no Manuscrito F I 31, de 1913, segundo o qual, como vimos, afirmar-se que «A existe» é o mesmo que afirmar que «existe um processo de possível legitimação da existência de A», não me parece ter sido substancialmente alterado; diria, por este motivo, que estamos em presença, nas Meditações Cartesianas, de um aprofundamento da análise intencional. Todavia, a referência à necessidade de um "processo de legitimação» - que, aliás, apenas reforça a tese de Ideias I de que o ser é sempre ser para uma consciência - não funda necessariamente um idealismo transcendental como o que é proposto nas Meditações Cartesianas. De facto, as Meditações propõem-nos a tese da relatividade do mundo, não porque a consciência deva legitimar os seus modos de aparição, mas sim porque tais modos são, eles próprios e enquanto tais, relativos ${ }^{8}$.

O Manuscrito B IV 6, de 1918, que citei anteriormente, constitui, em meu entender, um dos elos de ligação entre as formulações de idealismo de 1913 e a que encontramos em 1931 nas Meditações Cartesianas. No Manuscrito, aliás, deparamos com uma distinção que não detecto nesta última obra, entre as universalidades eidéticoformais e eidético-materiais. Interessam-me aqui estas últi-

\footnotetext{
${ }^{8}$ É, em minha opinião, o que nos diz Husserl (1950a, pp. 77 e segs.), com a sua conhecida análise da percepção de um cubo, se destina a comprovar. O carácter «subjectivo» das sucessivas aparições de um mesmo cubo (ora visto de um lado, ora visto do lado oposto, ora visto de perto, ora visto à distância, etc.) não se deve a qualquer peculiaridade do modo humano de conhecer, mas sim à natureza da própria coisa que é percepcionada.
} 
mas. Pensemos, seguindo o exemplo de Husserl, no eidos «cor» (HUSSERL 2003, p. 147). Ele só pode ser dado a um sujeito possível se uma cor fáctica singular puder ser captada pelos sentidos; é na sequência de uma tal captação que, numa livre actividade (a que Husserl chamava actos de ideação, nas Investigações Lógicas), o eidos «cor» é engendrado, bem como qualquer modificação de fantasia de uma cor real. Mas, no referido manuscrito, Husserl parece ter ainda mais alguma coisa a dizer sobre este assunto.

À ideia da corrente de consciência de um sujeito real ou possível pertence a distinção entre hylé e morphé, bem como a distinção entre neutralidade e posicionalidade, entre várias outras. Estas distinções, porém, não valem para as universalidades eidético-formais, como é o caso, por exemplo, dos números. Husserl diz:

Se existe um número da série dos números, ou uma proposição como proposição, tal exige a possibilidade de actos nos quais objectos ideais deste tipo sejam dados, mas não a realidade desses actos. Sou eu, certamente, quem reconhece essa possibilidade, por exemplo, o ser ideal da proposição " $2<3$ ”. Mas, quer eu viva na fantasia e nada ponha da realidade, quer eu fantasie dois centauros e três ninfas, já não sou propriamente o sujeito real cuja experiência real combate contra estas fantasias. (HUSSERL 2003, p. 149)

Nestes exemplos, a hylé e os seus conteúdos permanecem «fora de acção». Porém, tratando-se de idealidades eidético-materiais, as modificações de fantasia que engendram tais universalidades apenas serão possíveis se, por uma necessidade eidética, tiverem sido previamente dadas as impressões sensíveis correspondentes e se a elas corresponderem diferentes formas de adumbramento de um mesmo objecto. Ora acontece que tais adumbramentos são em número ilimitado, a possibilidade de novos adumbramentos está permanentemente em aberto, pelo que a 
possibilidade de existir um núcleo invariante que os remeta para um mesmo pólo de identidade - sem o que não seriam adumbramentos de coisa nenhuma e o objecto visado deveria ser declarado inexistente - exige a presença de uma consciência. No § 18 das Meditações Cartesianas, Husserl (1950a, p. 80) acentua ainda o facto de qualquer objecto ser uma realização intencional.

Será preciso regressar a uma análise dos $\$ \$ 55$ e 86 de Ideias $I$, aos quais já anteriormente fiz referência, para verificar se a doutrina husserliana da constituição deveria ou não ter uma interpretação idealista, naquela acepção do termo idealismo que Husserl classifica, ora como «idealismo metafísico», ora como «idealismo subjectivo». (Adicionalmente, poder-se-ia dizer que a versão da teoria da constituição que encontramos nas Investigações Lógicas seria dificilmente compatível com uma interpretação idealista deste tipo.) Ora, toda unidade real é uma unidade de sentido, como afirma Husserl no $\$ 55$ de Ideias I, e esta, por sua vez, pressupõe uma consciência doadora de sentido (HUSSERL 1950 b, p. 134). Por isso, continua,

A quem objectar, em face das nossas considerações, que tal significaria transformar a totalidade do mundo numa aparência subjectiva e lançar-se nos braços de um «idealismo berkeleyano», a tal pessoa só poderíamos replicar que não captou o sentido destas considerações. (HUSSERL 1950b, p. 134)

Parece claro que não se trata, com o idealismo fenomenológico de Husserl, de negar o mundo exterior, mas sim de corrigir as interpretações absurdas que conduzem à sua absolutização filosófica, a qual se opõe inclusive à consideração natural do mundo, que permanece alheia a uma tal absolutização. A tese natural nada tem de absurdo, necessitando apenas de uma fundamentação que a redução tem 
por objectivo proporcionar. Será esta que mostrará que só a consciência traz em si, em última instância, o sentido do mundo e de um mundo que efectivamente é, por conseguinte, transcendendo a consciência e permanecendo necessariamente transcendente (HUSSERL 1950a, p. 97). Permanece todavia o facto de a teoria da constituição ter sido apresentada por Husserl como a única configuração rigorosamente científica de idealismo. Está aqui em causa o que Husserl, por diversas vezes, chamou o «enigma da transcendência», ou o «enigma do conhecimento». De uma forma relativamente simples, podemos enunciar assim tal enigma: «como é que sendo a percepção um estado meu, posso afirmar, baseado nela, que existem tais e tais coisas, com tais e tais características?» (HUSSERL 2003, p. 41) O idealismo fenomenológico constitui a resposta de Husserl a esta pergunta.

Um curto texto de 1909, o Manuscrito K II 1, onde a questão anterior é explicitamente formulada, é muito interessante para avaliarmos o que será o «idealismo fenomenológico» cujos traços essenciais Ideias I exporá quatro anos mais tarde. Porque Husserl defende aí claramente que existe uma distinção a fazer entre a marcha da realidade efectiva e o chamado decurso lógico das minhas vivências, onde aquela se constitui. As Teses que mais acima chamei 1 e 2 supõe o reconhecimento desta distinção e, na verdade, sem ela não fariam sentido. O idealismo de Ideias I fornece, em meu entender, uma resposta correcta à pergunta formulada. "Transcendência», defende Husserl, é o nome para um conjunto de unidades de sentido, que remetem para certas conexões da consciência absoluta, as quais dão sentido e comprovam a validade do sentido. Trata-se, por conseguinte, de unidades ideais objectivas, que não são componentes 
reais dos actos em que foram engendradas, nem se identificam com os objectos reais.

$\bigcirc \S 86$ das Ideias, a que me irei referir para concluir, trata dos «problemas funcionais» da fenomenologia, ou, como Husserl corrige na margem de um dos seus exemplares da obra, dos "problemas constitutivos». Husserl alerta para o sentido especificamente fenomenológico, e não matemático, do termo "função», embora algo do sentido matemático do termo, mesmo que de uma forma muito lata na medida em que a noção de função inclui a noção de relação -, esteja ainda presente. De facto, a noção fenomenológica de função parece apontar para a relação que se estabelece entre a vivência de um objecto singular e a ideia que teleologicamente comanda a multiplicidade das suas aparições; a função torna possível a unidade sintética destas aparições e, por conseguinte, o noema como unidade de sentido. Trata-se de averiguar como:

[...] Segundo leis essenciais absolutamente fixas um objecto existente é o correlato de conexões de consciência com um conteúdo essencial perfeitamente determinado, assim como, ao invés, o ser de conexões de tal índole é equivalente a um objecto existente. (HUSSERL 1950b, p. 214)

Não sei até que ponto Husserl terá estado consciente da profunda ambiguidade desta frase. Pois se a sua primeira parte postula um idealismo gnosiológico, totalmente compatível com um realismo metafísico - podendo todavia, como não seria provavelmente a intenção de Husserl, receber uma interpretação metafísica de um outro tipo -, já a sua segunda parte me parece apontar claramente para uma forma de idealismo que não é apenas a do «idealismo fenomenológico». Ou seja, a acepção em que entendemos a relação da consciência com as objectividades que ela consti- 
tui não me parece ser a mesma - ou, pelo menos, parece-me poder não ser a mesma - nos dois casos. Daí que a discussão sobre o que entendemos pelo idealismo de Husserl ainda prossiga.

Abstract: This paper addresses the meaning of Husserl's idealism between the Ideas of 1913 and the Cartesian Meditations of 1931. In the work of 1913, the idealism stems from a distinction between consciousness and world based in a difference in the corresponding modes of giveness: consciousness gives itself absolutely and without profiles, and the world is given as an identity pole of a multiplicity of profiles. The fact that Husserl offered a second definition of his idealism in the same work proves that he thought the first one was not sufficient to ground the kind of idealism he was committed to. According to this second definition, consciousness is an absolute being that nulla res indigent ad existendum, while the world has a relative and contingent being. In 1931 the Cartesian Meditations give the final clue to the understanding of these earlier definitions. Husserls sharply distinguishes his phenomenological idealism from the Berkeleyan and Kantian ones and defines it as a thorough explicitation of the Ego as a constitutive agency, so that the "world that really is» is «the world constituted by consciousness».

Keywords: Idealism; intencional analysis; profiles; constitution.

\section{BIBLIOGRAFIA}

BRENTANO, Franz, Psychology from an Empirical Standpoint (trad. de Antus C. Rancurello, D. B. Terell e Linda L. McAlistar). London and New York: Routledge, 2005.

HUSSERL, Edmund, Cartesianische Meditationen (Husserliana Band I). Den Haag: Martinus Nijhoff, 1950a.

Ideen zu einer reinen Phänomenologie und phänomenologischen Philosophie, Erstes Buch (Husserliana Band III). Den Haag: Martinus Nijhoff, 1950b.

Die Krisis der europäischen Wissenschaften und die Transzendentale Phänomenologie (Husserliana Bnad VI). Den Haag: Martinus Nijhoff, 1954. 
Zur Phänomenologie des inneren Zeitbewusstsein (Husserliana Band X). Den Haag: Martinus Nijhoff, 1966.

Transzendentaler Idealismus (Husserliana Band $\overline{\mathrm{XXXVI})}$. Dordrecht / Boston / London: Kluwer Academic Publishers, 2003.

RUSSELL, Bertrand, «On the nature of acquaintance», in Logic and Knowledge, London, Routledge, 2001, pp. 125174.

SOKOLOWSKI, Robert, The Formation of Husserl's Concept of Constitution. The Hague: Martinus Nijhoff, 1964. 